\title{
Análisis sobre el marco jurídico que regula el aprovechamiento forestal en Colombia ${ }^{1}$
}

\section{Analysis on the legal framework which regulates forest use in Colombia}

\author{
Lisneider Hinestroza-Cuesta ${ }^{2}$, Marisela Mena-Valencia ${ }^{3}$
}

\begin{abstract}
Resumen
En el país existe una amplia normatividad ambiental que frecuentemente es desconocida en la ejecución de actividades y proyectos que implican un riesgo de deterioro ambiental y de impacto negativo sobre los recursos naturales y la diversidad biológica. Abordando una investigación documental, se revisó y analizó el marco jurídico forestal colombiano, la aparición y evolución de las normas jurídicas sobre aprovechamiento forestal relacionadas con los bosques y flora silvestre, y la legislación aplicable a comunidades negras frente al aprovechamiento de los recursos forestales. Identificando como autoridades con competencia en materia forestal a los Ministerios de Ambiente y Desarrollo Sostenible, y de Agricultura y Desarrollo Rural, los dos cuerpos legales vigentes, más importantes para la gestión de los recursos forestales son: el Código Nacional de Recursos Naturales Renovables y de Protección al Medio Ambiente (Decreto 2811 del 18/10/1974) y el Régimen de Aprovechamiento Forestal (Decreto 1791 del 04/10/1996).
\end{abstract}

Palabras clave: Aprovechamiento forestal; Régimen legal; Bosques; Flora silvestre.

\begin{abstract}
In Colombia there is an ample environmental legal framework which is disregard frequently in the performance of activities and projects. The aforementioned disregard implies risks of environmental deterioration and negative impact on natural resources and biological diversity. In this sense, a documental research was carried out, by which it was examined and analysed the legal framework of forest use in Colombia, the origin and evolution of the legal norms on forest use, specifically in relation with woods and wild flora. Furthermore, it was examined the legislation applicable to black communities in respect to the use of forest resources. This research has also identified as authorities with competence in forest affairs, the Ministry of Environment and Sustainable Development, and the Ministry of Agriculture and Rural Development. Finally, the two most important legal bodies in existence, which regulate forest use in Colombia, are the National Code of Renewable Natural Resources and Protection of Environment (Decree 2811 of 10/18/1974) and the Legal Regime of Forest Use (Decree 1791 of 10/04/1996).
\end{abstract}

Keywords: Forest use; Legal regime; Woods; Wild flora.

\section{Introducción}

Colombia pertenece a la «familia de la megabiodiversidad» junto con Brasil, Indonesia, Malasia, México, Zaire, Magadascar, Perú y Venezuela; más del 10\% de las especies del planeta están representadas en Colombia y muchas de ellas son endémicas, es decir, exclusivas del país, pero la mayor parte de esa biodiversidad está en el bosque y se sustenta de él (Pizano s.f).

1 Este artículo es producto de la investigación «Estudio jurídico sobre el otorgamiento de permisos de aprovechamiento forestal en territorios colectivos de comunidades negras en el Chocó 2004-2009» en el marco de la Beca Pasantía de Joven Investigador otorgada por el Departamento Administrativo de Ciencia Tecnología e Innovación (COLCIENCIAS), Bogotá, Colombia.

2 Grupo de Investigación Derecho, Sociedad y Medio Ambiente (GIDSMA). Docente, Programa de Derecho, Universidad Tecnológica del Chocó, Quibdó, Colombia. e-mail: lisneider@yahoo.es

3 Grupo de Investigación Derecho, Sociedad y Medio Ambiente (GIDSMA). Joven Investigadora Colciencias Convocatoria $\mathrm{N}^{\circ}$ 510, Programa de Derecho, Universidad Tecnológica del Chocó, Quibdó, Colombia. e-mail: maryvale_05@hotmail.com Fecha recepción: Noviembre 25, 2011 Fecha aprobación: Diciembre 20, 2011 
De acuerdo con el Estudio FRA 2005, Colombia aún conserva el $58 \%$ de su territorio Nacional cubierto de bosques, lo que equivale a más de $60 \mathrm{mi}-$ llones de hectáreas (Antonissen 2010 p. 13). Sin embargo, tal y como lo expresa Pizano (s.f), el país enfrenta un desafío ante el futuro del recurso forestal, en términos de generar modelos sostenibles para los ecosistemas del bosque tropical húmedo.

Teniendo en cuenta lo planteado por el Pacto Intersectorial por la Madera Legal en Colombia (2010), durante los últimos diez años Colombia se ha posicionado, poco a poco, como uno de los países pioneros a nivel de Latinoamérica que han optado por el reto de asumir una serie de disposiciones, leyes y mecanismos encaminados hacia el aprovechamiento sostenible de los bosques tropicales y el manejo ambiental de cultivos forestales, por lo que hoy en día, se habla de Colombia como un país con vocación forestal, ya que alrededor del 50\% del territorio nacional tiene cobertura forestal, concentrada principalmente en tierras colectivas de comunidades indígenas y afrodescendientes del ChocoDarién y la cuenca del río Amazonas. Esta cobertura, equivalente al $29 \%$ de los bosques del mundo, constituye una gran oportunidad de desarrollo sostenible en el país, siempre y cuando su aprovechamiento beneficie a las comunidades nativas locales $\mathrm{y}$ fortalezca las iniciativas de pequeñas, medianas y grandes empresas.

Sin embargo, factores como el acelerado crecimiento poblacional, el impacto ambiental de macroproyectos de infraestructura vial, hidroeléctrica y urbanística, la ampliación de la frontera agrícola, la ganadería intensiva y el sobrepastoreo, el tráfico de especies silvestres, las plantaciones de especies vegetales para biocombustibles, los cultivos ilícitos, la quema y la tala indiscriminada e ilegal de bosques, entre otros, afectan de manera considerable el desarrollo de proyectos que incluyan prácticas como la extracción y comercialización legal de madera bajo un plan de aprovechamiento sostenible, y consecuentemente inciden en la sostenibilidad integral de nuestros bosques nativos (Pacto Intersectorial por la Madera Legal en Colombia 2010).

La tala ilegal y el comercio asociado son cuestiones complejas que tienen graves consecuencias ambientales, sociales y económicas. La falta de observancia y aplicación de la legislación forestal con- tribuye a menudo a provocar una fuerte degradación de los bosques y deforestación, que causan pérdida de hábitats y de biodiversidad, degradación del suelo y alteración de los servicios suministrados por los ecosistemas forestales. Esto, a su vez, incide negativamente en las poblaciones rurales y, en particular, en las comunidades más pobres que dependen de los bosques (Pacto por los Bosques del País S.f.).

Con la creación del Ministerio de Medio Ambiente en el año 1993 y la posterior política de bosques en 1996, el país quiso dar un paso hacia la ordenación de este vital recurso natural, un tema que desde la misma época de independencia ya se evidenciaba como una preocupación de estado, como lo demuestra el Decreto Medidas de protección y mejor aprovechamiento de la riqueza forestal de la Nación, expedido por el Libertador en 1829.

Hoy, luego de la primera década del siglo XXI, los bosques como factores clave del escenario mundial de protección al medio ambiente toman un nuevo impulso en los debates mundiales y Colombia, tercer país por superficie de bosque en América Latina y el Caribe, no puede ser ajeno a ello (Ministerio de Ambiente Vivienda y Desarrollo Territorial 2011).

A pesar de que en Colombia en la actualidad se cuenta con una amplia normatividad ambiental dirigida a materializar los mandatos constitucionales y los compromisos internacionales adquiridos por el Estado colombiano, relacionados con la protección y conservación del ambiente y de los recursos naturales, tales normas en materia de bosques y de flora silvestre son desconocidas con frecuencia en la ejecución de actividades y proyectos que implican un riesgo de deterioro ambiental y de impacto negativo sobre los recursos naturales y la diversidad biológica; por tanto a continuación se presenta un análisis y/o reflexión de este marco normativo.

\section{Metodología}

Se utilizó la investigación documental, propuesta por Toro y Parra (2010) que supone la revisión cuidadosa y sistemática de estudios, informes de investigación y literatura existente, contextualizándola para lograr estar al día sobre lo que circula en el medio en relación con lo que se investiga. Para lo anterior se revisaron las disposiciones y normas le- 
gales relativas al aprovechamiento forestal en el país, a partir del análisis de fuentes formales del Derecho: leyes, decretos, acuerdos, resoluciones y jurisprudencia de la Corte Constitucional sobre el tema y de fuentes inmediatas atendiendo a la doctrina como libros e informes de consultorías.

\section{Desarrollo}

Antecedentes normativos de la regulación de la actividad forestal en Colombia. Desde el inicio, el aprovechamiento forestal ha sido objeto de una nutrida reglamentación (Ministerio del Medio Ambiente 1994) aunque en principio, las normas eran analizadas según las entidades encargadas de administrar el recurso. Durante la primera mitad del siglo XX esta actividad estuvo a cargo del Ministerio de Economía Nacional y en la década de los cincuenta pasó al Ministerio de Agricultura. A finales de los sesenta se creó el Instituto Nacional de los Recursos Naturales Renovables y del Medio Ambiente (INDERENA), entidad que hasta la creación del Ministerio del Medio Ambiente en 1993, fue la encargada de administrar los bosques, junto con las corporaciones autónomas regionales (Ministerio del Medio Ambiente 2002).

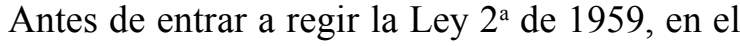
ordenamiento colombiano los primeros vislumbramientos en cuanto a la explotación de los bosques empezaron en 1919 con la Ley 119 del 30 de diciembre, mediante la cual se reformó el Código Fiscal de 1912, en la parte de explotación de bosques, se crearon las reservas forestales, se establecieron los contratos de arrendamiento, las licencias y los permisos sobre bosques nacionales como modo de adquirir el derecho a su utilización por parte de los usuarios. Además esta ley establecía como bosques nacionales las plantaciones naturales de caucho, tagua, pita, henoquéa, quina, balata, jengibre, maderas preciosas y demás productos de exportación o de consumo interior, existentes en terrenos de la Nación (Ministerio del Medio Ambiente 2002).

Luego, surge el Decreto 272 de 1920, reglamentario de la Ley 119, que señaló como obligación de los concesionarios de los bosques nacionales elaborar una relación completa de los productos extraídos de los bosques así como de la destinación de estos productos, en el mercado interno e internacional. Asi- mismo, establecía que en cada contrato se señalaría el porcentaje que correspondía al gobierno cuando se tratara de explotación de maderas, piratas u otros productos semejantes; de igual forma, fijó el límite del diámetro de los árboles que se permitía cortar en un área forestal dada, lo que variaba según las especies de los árboles, las condiciones del bosque y las necesidades de cada localidad en general, prohibiendo así, para madera los árboles menores de cuarenta centímetros de diámetro. Para asegurar el cumplimiento de las obligaciones de los concesionarios de explotación de bosques, este decreto consagró una caución a favor del Gobierno que no debería ser menor de quinientos pesos $(\$ 500.00)$ moneda corriente dentro del término de dos meses contados desde la aprobación definitiva de los contratos, suma que perdura en favor del tesoro nacional en caso de no cumplir algunas de las cláusulas estipuladas (República de Colombia 1920). Producto de este decreto surge el 2227 de 1920 reformatorio del Decreto 272 de 1920, que señaló 15,000 ha como límite máximo del área objeto del contrato.

Más adelante, se expide la Ley 74 de 1926, sobre explotación de bosques nacionales. En esta ley, se determinaron 10 años como período máximo de arrendamiento de bosques nacionales. La Ley 74 de 1926 autorizó al Gobierno Nacional para comprar, por intermedio del Banco Agrícola, haciendas mayores de 500 ha situadas cerca de los centros urbanos, con la intensión de subdividirlas entre los arrendatarios y ocupantes. Esta parcelación empezó desconociendo los objetivos económicos y sociales que favorecieran el desarrollo agrícola del país y el bienestar del labriego (Ortiz s.f).

Años más tarde, aparece la Ley 93 de 1931, mediante la cual se fomentó la explotación de productos forestales de bosques nacionales, fijó como obligación del contratista la de fomentar la colonización y mejoramiento de los bosques nacionales, de igual forma esta ley estableció para los individuos que personalmente se dedicaran a hacer pequeñas explotaciones de productos forestales como ipecacuana, canime, resina de algarrobo, caucho, etc., el deber de llevarlos a cabo mediante permisos anuales obtenidos del alcalde del municipio dentro del que se hallaba ubicado el bosque explotable antes de emprender la explotación, se comprometen a dar cuenta de los productos extraídos y a pagar los impuestos 
correspondientes. Estos impuestos eran cubiertos en la oficina de recaudación de hacienda nacional del respectivo municipio, y no eran mayores que los señalados para las explotaciones en grande escala (República de Colombia 1931).

Consecuente con otras normas, el Decreto 1454 de 1942, impuso que para que un dueño, arrendatario o concesionario pudiera aprovechar el bosque público o privado tenía que tener autorización del Ministerio de Economía Nacional, entidad que para otorgar el permiso tenía que establecer la capacidad de área boscosa y que la explotación se ajustara a normas técnicas procurando el beneficio social y económico de la utilización. Siendo así, el término para las licencias, contratos o permisos estaría determinado por el Gobierno de acuerdo con la naturaleza del producto y de la industria a la cual abasteciera.

En 1946, el Decreto 284, estableció que a partir de su vigencia toda explotación debía estar autorizada por el Ministerio de Economía. Si faltaba este requisito la explotación no podía ser tenida en cuenta para posteriores procesos de adjudicación como prueba de explotación económica. De igual forma, dispuso que los productos extraídos sin el permiso correspondiente podían ser decomisados por los inspectores de bosques.

El Decreto 2921 de 1946 fijó la extensión mínima de los permisos en 500 ha y la máxima en 15,000 ha. El área podía ser sujeta a otro dimensionamiento si la densidad del bosque era comercialmente explotable, o en virtud de la naturaleza de la industria a la que abasteciera el producto, estableció un plazo de 12 meses para que el extractor pudiera evaluar la no comercialidad de la explotación. El mismo instrumento consagró que los pequeños extractos podían tener derecho a aprovechamientos de menor área; esta norma estableció el salvoconducto de movilización de maderas.

En 1953 se reglamentó el Decreto 2278 de 1953, que condensó la normatividad anterior y estableció que el aprovechamiento se realizaría bajo parámetros técnicos que garantizaran su conservación y procuraran al máximo los beneficios sociales y económicos. La explotación de los bosques requería de licencia previa del Ministerio de Agricultura.

Mediante la Resolución 876 de 1957 del Ministerio de Agricultura se condicionó el otorgamiento de la licencia por parte de ese ministerio, al concepto técnico de un profesional forestal designado para el efecto. Este funcionario debía rendir un dictamen acerca del área, linderos y ubicación, condiciones físicas y climatológicas. Las solicitudes de concesión debían acompañarse de un plan de aprovechamiento, firmado por un profesional forestal.

Este compendio de normas, se puede considerar como la primera fase de reglamentación de la actividad forestal en el país; en esta primera etapa, el aprovechamiento forestal en el país fue producto de la aplicación de un procedimiento administrativo realizado ante las instancias administradoras de los recursos naturales y más específicamente del recurso forestal. Al INDERENA desde su creación en 1968, se le asignó la función de determinar los requisitos y los procedimientos que debían cumplirse por parte de los usuarios del bosque, más adelante esta función fue ejercida, además, por las corporaciones autónomas regionales, cada una en los territorios de su jurisdicción.

Los antecedentes de la actividad forestal en Colombia se condensan entonces, a partir de la existencia de una gama de normas hoy derogadas y/o modificadas, que dieron luz a la expedición de leyes y decretos que han unificado con criterios más claros la materia forestal atendiendo las necesidades del país y su interés por proteger y conservar los recursos naturales renovables y el ambiente. En esta fase, se observa cómo en el país la administración del recurso forestal estuvo a cargo de varias entidades del estado, en donde mecánicamente, para explotar los bosques se tenía que recurrir a contratos de concesión y a figuras como el arrendamiento, las licencias y los permisos sobre bosques nacionales como modo de adquirir el derecho a su utilización por parte de los usuarios; producto de esto en el ordenamiento jurídico colombiano se empieza una etapa en donde se busca la consolidación de la normatividad ambiental, dejando de lado las normas anteriores y es allí donde se comienza a estructurar la política forestal nacional colombiana.

Estructuración legal de la actividad forestal en Colombia. Los orígenes de la estructuración legal de la política o actividad forestal en Colombia se remiten a la Ley $2^{\mathrm{a}}$ de 1959 que creó las zonas de reserva forestal República de Colombia (1959); en esta norma se estableció la obligación de elaborar 
planes de ordenación de los bosques, la licencia expedida por el Ministerio de Agricultura para los aprovechamientos forestales y la obligación a los permisionarios de presentar planes de manejo forestal.

En este orden de ideas, las primeras acciones en cuanto al manejo y conservación de los bosques comenzaron a estructurarse desde 1959 con la promulgación de la Ley $2^{\mathrm{a}}$ o Ley «Sobre economía forestal de la Nación y conservación de los recursos naturales renovables» significando un paso importante, porque se crearon siete reservas forestales en una extensión de 65,000 ha, 275,000 ha de reservas forestales protectoras, 453 ha de reservas forestales productoras y 17,000 ha de reservas manejadas por la sociedad civil para el logro de objetivos enfocados hacia la protección y desarrollo económico (Murillo 2008), como la declaración de siete grandes reservas forestales: el Pacífico, la zona Central, el río Magdalena, la Sierra Nevada de Santa Marta, la Serranía de los Motilones, Cocuy y la Amazonía. Estas zonas de reserva forestal se encuentran actualmente vigentes y sus áreas se consideran patrimonio forestal del país, pero han sido objeto de reiteradas sustracciones parciales a través de los años (Ucros 2008).

La Ley $2^{\text {a }}$ de 1959 , en materia forestal, estableció un plazo de 12 meses para que los concesionarios o permisionarios de bosques presentaran un plan de manejo forestal; si no lo hacían podía decretarse la caducidad del contrato.

Como lo expone Murillo (2008) esta ley ha significado un paso importante, definió siete zonas de reservas forestales con el propósito de proteger recursos naturales estratégicamente valiosos desde el punto de vista ambiental, de su riqueza como biodiversidad y por tanto de la necesidad de su conservación ecológica. Sin embargo, también ha sido muy criticada porque a pesar de la importancia de estos territorios para el desarrollo forestal y el mantenimiento del patrimonio biótico, ambiental y cultural del país, su manejo y administración no ha sido consecuente con esta condición, pues la mayoría de las acciones administrativas desde su creación, se refieren a actos legales de sustracción de territorios en múltiples eventos, que han ocasionado la disminución de los territorios, sobre todo para atender procesos de colonización de tierras, en donde se han excluido áreas no siempre con vocación agrícola o pecuaria (Ministerio de Ambiente, Vivienda y Desarrollo Territorial s.f).

Continuando con las normas que en Colombia se han expedido en materia ambiental, específicamente sobre bosques y/o aprovechamiento forestal, en 1973 surge la Ley 23, que concedió las facultades para la expedición del Código Nacional de los Recursos Naturales y de Protección al Medio Ambiente que es objeto de revisión más adelante, con el que se regularon políticas que reforzaron tal concepto, como el Decreto 622 de 1997 con la creación del Sistema de Parques Naturales que en el Artículo 328 le consagra la misión de garantizar la estabilidad ecológica y mantener una prueba representativa de los ecosistemas presentes en el país (Parques Nacionales Naturales de Colombia 2010); el Decreto 2925 de 1994 con el que se crea la Unidad Administrativa del Sistema de Parques Nacionales Naturales de Colombia (UAESPNN) con el objeto de conservar la flora y fauna nacional, al igual que introduce el Sistema de Parques Nacionales Naturales, declarándoles como aquellas zonas que el Gobierno Nacional, por intermedio del Ministerio de Agricultura, previo concepto favorable de la Academia Colombiana de Ciencias Exactas, Físicas y Naturales, delimite y reserve de manera especial, por medio de decretos, en las distintas zonas del país y en sus distintos pisos térmicos, y en las cuales quedará prohibida la adjudicación de baldíos, las ventas de tierras, la caza, la pesca y toda actividad industrial, ganadera o agrícola, distinta a la del turismo o a aquellas que el Gobierno Nacional considere convenientes para la conservación o embellecimiento de la zona. Dentro de estos parques pueden crearse reservas integrales biológicas, en los casos en que ello se justifique a juicio del Ministerio de Agricultura y de la Academia de Ciencias Exactas, Físicas y Naturales (Murillo 2008).

Según lo planteado por Murillo (2008), los planes y políticas forestales de mayor relevancia se han generado desde la década del setenta, con la creación del INDERENA, Instituto Colombiano de la Reforma Agraria (INCORA) que hoy se conoce con el nombre de Instituto Colombiano de Desarrollo Rural (INCODER) y la Corporación Nacional de Investigación y Fomento Forestal (CONIF), principales instituciones para el apoyo y desarrollo de la in- 
vestigación forestal en Colombia, que luego vendrían a ser reformadas por la Ley 99 de 1993.

Con la expedición del Decreto Ley 2811 de 1974 a raíz de la Ley 23, posteriormente, en materia de política forestal, el Código Nacional de Recursos Naturales Renovables y de Protección al Medio Ambiente (Decreto Ley 2811 de 1974) determinó las áreas de reserva forestal (productoras, protectoras y productoras-protectoras) y prohibió en estas la adjudicación de baldíos, salvo por razones de utilidad pública e interés social, siendo necesario delimitar y sustraer previamente las áreas respectivas. Igualmente definió los aprovechamientos forestales (persistentes, únicos y domésticos), que se pueden adelantar en terrenos de dominio público, previo el otorgamiento de permisos o a través de concesiones o asociaciones, y en los predios de propiedad privada deber ser autorizados por la autoridad ambiental, al expresar lo siguiente:

Artículo 213: Son aprovechamientos forestales persistentes los que se efectúan con la obligación de conservar el rendimiento normal del bosque con técnicas silvícolas que permitan la renovación del recurso.

Artículo 214: Son aprovechamientos forestales únicos los que técnicamente se realicen en bosques localizados en suelos que deban ser destinados a usos diferentes del forestal.

De igual forma establece en este articulado: $« E l$ permiso para aprovechamiento forestal único puede contener la obligación de dejar limpio el terreno al acabarse el aprovechamiento, pero no la de renovar o conservar el bosque».

Artículo 215: Son aprovechamientos forestales domésticos, los que se efectúan exclusivamente para satisfacer necesidades vitales de uso doméstico.

Asimismo dispone: «No podrá comerciarse en ninguna forma con los productos de este aprovechamiento. «El aprovechamiento forestal doméstico deberá hacerse únicamente con permiso otorgado directamente al solicitante previa inspección, con un año de duración y con volumen máximo de veinte metros cúbicos anuales».

Con el Decreto Ley 2811, se refundió casi en su totalidad la normativa del sector ambiental colombiano en un solo cuerpo jurídico coherente, es decir, con el Código de Recursos Naturales y de Protección al Medio Ambiente y se logró una estructura normativa básica, elaborada con unidad de criterios $\mathrm{y}$ con arreglo a los principios de funcionamiento del Estado en materia ambiental (Ucros 2008).

En este sentido y como lo reafirma Murillo 2008, otro paso importante viene a darse en la planificación de los recursos forestales del país con fines a la articulación de la política ambiental en Colombia, dada por hecho en la promulgación del Decreto 2811 de 1974, que regula desde su Artículo 199 hasta el 246, la flora silvestre, de tal forma que la define como «el conjunto de especies e individuos vegetales del territorio nacional que no se han plantado o mejorado por el hombre». También uniforma aspectos atinentes a los bosques, áreas de reserva forestal, industrias forestales, reforestación, asistencia técnica forestal, investigación forestal, comercialización de productos forestales, protección forestal, al igual que codifica los aprovechamientos forestales al contemplar:

Artículo 211: Se entiende por aprovechamiento forestal la extracción de productos de un bosque.

Vale la pena resaltar, que los tipos de aprovechamiento forestal, atendiendo las disposiciones del Decreto 2811 de 1974 pueden ser persistentes, únicos o domésticos.

Aunado a lo anterior, no hay que desconocer que muchos de los postulados y principios contenidos en el Decreto Ley 2811 de 1974 se introdujeron como elementos de política y aportes a la Constitución de 1991 y la Ley 99 de 1993, como por ejemplo, el derecho de todas las personas a disfrutar de un ambiente sano, el desarrollo socioeconómico y cultural, el fortalecimiento de los sistemas ambientales, la creación de áreas de manejo especial, la promoción y preservación de la calidad de vida y la protecciones de los bienes y riquezas ecológicos, naturales y culturales, entre otros.

De esta forma, es en el año 1974, con la expedición del Código de los recursos naturales renovables y del ambiente (Decreto Ley 2811 1974) que el Sistema de Parques Nacionales Naturales adquiere un cuerpo normativo coherente en el que se definen las finalidades del Sistema, las cinco categorías de manejo (Parque Nacional, Reserva Natural, Área Natural Única, Santuario de Flora y Fauna, y Vía Parque), las actividades permisibles, se asignan funciones al Gobierno Nacional y a la autoridad ambiental para su protección y manejo, y se determi- 
nan las disposiciones generales de su régimen (Díaz 2008).

Por lo anterior, la década de los setenta es la época que ha marcado un hito importante en cuanto a la política forestal del país, surge para ratificar ese pensamiento el Decreto 877 del 10 de mayo de 1976, por medio del cual se señalan prioridades referentes a los diversos usos del recurso forestal, a su aprovechamiento y al otorgamiento de permisos y concesiones, y se dictan otras disposiciones. En esta norma se establece que el recurso forestal debe ser destinado en principio a satisfacer necesidades como las vitales de uso doméstico, de conservación y protección del recurso forestal y de otros recursos relacionados con aquel, mediante la creación de las reservas a que se refiere el artículo 47 del Decreto Ley número 2811 de 1974 y las de atención a los requerimientos de la industria, de acuerdo con los planes de desarrollo nacionales y regionales. De igual forma consagra este decreto, en su Artículo 2, dentro de sus aspectos más relevantes, que en las áreas de reserva forestal solo podrá permitirse el aprovechamiento persistente de los bosques; también, establece las prioridades para el otorgamiento de permisos y concesiones de aprovechamiento forestal que deben ceñirse de conformidad con lo establecido por los artículos 56, 220 y 234 del Decreto 2811 de 1974, al contemplar que el INDERENA, al otorgar permisos o concesiones de aprovechamiento forestal, deberían tener en cuenta las siguientes prioridades: a) El haber realizado los estudios sobre el área objeto de la solicitud de aprovechamiento forestal; b) El haber establecido la plantación forestal industrial sobre el área objeto de la solicitud, y c) El tener mayor proporción de capital nacional. En el mismo sentido contempla los criterios para la elección entre varios solicitantes de permisos de aprovechamiento forestal.

Al igual que en el ordenamiento interno nacional, existen unas convenciones que a nivel internacional han sido ratificadas por Colombia y que han dado origen a unas leyes internas que le dan cierta importancia a los recursos de la flora y fauna del país como es el caso de la Ley 17 de 1981, mediante la que se aprueba la «Convención sobre el Comercio Internacional de Especies Amenazadas de Fauna y Flora Silvestre», suscrita en Washington, DC, el 3 de marzo de 1973, en la cual los estados contratan- tes, reconocieron que la fauna y la flora silvestre, en sus numerosas, bellas y variadas formas constituyen un elemento irremplazable de los sistemas naturales de la tierra, y plantean que tienen que ser protegidas para esta generación y las venideras; asimismo, reconocen el creciente valor de la fauna y flora silvestre desde los puntos de vista estético, científico, cultural, recreativo y económico; sostienen que los pueblos y estados son y deben ser los mejores protectores de su fauna y flora silvestres y enfatizan que la cooperación internacional es esencial para la protección de ciertas especies de fauna y flora silvestre contra su explotación excesiva mediante el comercio internacional.

Consecuentemente, se expidió en año 1982 el Decreto 1014 sobre permisos de aprovechamiento forestal; en su Artículo $2^{\circ}$ dispuso: «serán objeto de permiso, los aprovechamientos forestales persistentes de bosques naturales o artificiales localizados en baldíos y demás terrenos de dominio público, sobre áreas hasta de 10,000 hectáreas y por un término no mayor de diez (10) años», pero el artículo fue modificado por el Decreto 498 de 1985 quedando de la siguiente manera «Serán objeto de permiso, los aprovechamientos forestales persistentes de bosques naturales o artificiales localizados en baldios y demás terrenos de dominio público, por un término no mayor de diez (10) años». De igual forma, establecía en el Artículo $3^{\circ}$ inciso $1^{\circ}$ : «Serán objeto de concesión, los aprovechamientos forestales persistentes de bosques naturales o artificiales ubicados en baldios y demás terrenos de dominio público, sobre áreas superiores a 10,000 hectáreas y por un término hasta de treinta (30) años»; y en su inciso $2^{\circ}$, «No obstante, por razón de disponibilidad de la especie solicitada podrán las entidades administradoras de los recursos naturales renovables otorgar en concesión aprovechamientos forestales sobre extensiones inferiores a las previstas en el presente artículo». Luego, estos dos apartes fueron derogados por el Decreto 498 de 1985, en lo que respecta a los permisos de aprovechamiento forestal y las regulaciones que debe contener la resolución o el contrato que otorgue la concesión. Sin embargo, no es claro en qué casos se aplica cada una de las regulaciones, su procedencia o condiciones y las causas generales que conducen a su caducidad (Ucros 2008).

En cuanto a la normatividad nacional que hoy 
es objeto de análisis y/o reflexión por su aporte a la política forestal, en 1989 se expidió la Ley 37, por la cual se dan las bases para estructurar el Plan Nacional de Desarrollo Forestal. A través de esta ley se creó el Servicio Forestal Nacional como un sistema de coordinación de las entidades públicas de los niveles territoriales encargadas de desarrollar las actividades establecidas por el Plan Nacional de Desarrollo Forestal. En ese mismo año, el Consejo Nacional de Política Económica y Social (CONPES), aprobó el Plan de Acción Forestal para Colombia (PAFC), que contó para su desarrollo con asignaciones provenientes del presupuesto nacional y de cooperación técnica internacional.

También se suscribe por Colombia la Declaración de la Cumbre de Río de Janeiro 1992 que bajo sus principios 1 y 4 establece que los seres humanos constituyen el centro de las preocupaciones relacionadas con el desarrollo sostenible, y que por lo mismo «Tienen derecho a una vida saludable y productiva en armonía con la naturaleza» (Principio 1) «Para alcanzar el desarrollo sostenible, la protección del medio ambiente debe ser parte del proceso de desarrollo y no puede ser considerado por separado» (Principio 4).

En dicha convención, los estados parte asumen unos compromisos; producto de estos surge entre otros, en nuestro país en el año 1993 la Ley 99, esbozando la política de Estado en materia de gestión ambiental, impulsando una relación más armónica y de respeto del ser humano con la naturaleza basada en el conocimiento, recuperación, protección, ordenación, uso y aprovechamiento de los recursos naturales con miras a hacer vigentes las directrices de desarrollo sostenible señaladas en la cumbre. A través de esta ley se crea el Ministerio del Medio Ambiente, se reordena el sector público encargado de la gestión y conservación del medio ambiente y los recursos naturales renovables, se organiza el Sistema Nacional Ambiental (SINA) y se dictan otras disposiciones. Por lo mismo, es a raíz de la Ley 99 de 1993, que posteriormente, se empezaron a forjar procesos encaminados a la jerarquización de la gestión del medio ambiente en el país (República de Colombia 1993a).

Continuando con el proceso de jerarquización y organización de la política forestal nacional, se expidió la Ley 139 de 1994, con la que se crea el certi- ficado de incentivo forestal (CIF), como un reconocimiento del Estado a las externalidades positivas de la reforestación en tanto los beneficios ambientales y sociales generados son apropiables por el conjunto de la población, siendo su fin el de promover la realización de inversiones directas en nuevas plantaciones forestales de carácter protector-productor en terrenos de aptitud forestal, reglamentada por el Decreto 1824 de 1994 y el Decreto 900 de 1997. El Decreto 1824 de 1994 trae disposiciones referentes a la elegibilidad de proyectos, otorgamiento y pago del incentivo forestal, al igual que contempla aspectos atinentes al plan de establecimiento y manejo forestal y contrato de ejecución del proyecto de reforestación, en tal sentido, establece que la elegibilidad es «la etapa que tiene como finalidad determinar si un proyecto de reforestación y la persona natural o jurídica que lo desarrolle son susceptibles de obtener el incentivo forestal» y el otorgamiento como el reconocimiento del derecho al incentivo forestal en favor de una persona natural o jurídica que haya evidenciado el cumplimiento de los términos y condiciones definidos en la Ley 139 de 1994 y en este decreto reglamentario. Vale la pena decir que de conformidad con este decreto la entidad encargada de pagar el incentivo forestal es el Fondo para el Financiamiento del Sector Agropecuario (FINAGRO). Por su parte el Decreto 900 de 1997 reglamenta el incentivo forestal con fines de conservación establecido en la Ley 139 de 1994 y el parágrafo del Artículo 250 de la Ley 223 de 1995, para aquellas áreas donde existan ecosistemas naturales boscosas, poco o nada intervenidos.

En 1996, el Ministerio del Medio Ambiente, hoy Ministerio de Ambiente y Desarrollo Sostenible y el Departamento Nacional de Planeación elaboraron la política de bosques, que fue aprobada por el CONPES. De allí que en relación con los productos forestales primarios y secundarios provenientes de bosques naturales y plantados se normalizó el artículo 5 de la Ley 99 de 1993 reglamentándose el Decreto 1791 de 1996, por medio del cual se establece el régimen de aprovechamiento forestal para Colombia, y se regulan las actividades de la administración pública y de los particulares respecto al uso, manejo, aprovechamiento y conservación de los bosques y la flora silvestre con el fin de lograr un desarrollo sostenible. Este precepto, se enmarca en unos prin- 
cipios que se traducen en lo siguiente:

a) Los bosques, en tanto parte integrante y soporte de la diversidad biológica, étnica y de la oferta ambiental, son un recurso estratégico de la Nación y por lo tanto, su conocimiento y manejo son tarea esencial del Estado con apoyo de la sociedad civil. Por su carácter de recurso estratégico, su utilización y manejo debe enmarcarse dentro de los principios de sostenibilidad consagrados por la Constitución Política como base del desarrollo nacional.

b) Las acciones para el desarrollo sostenible de los bosques son una tarea conjunta y coordinada entre el Estado, la comunidad y el sector privado, quienes propenderán porque se optimicen los beneficios de los servicios ambientales, sociales y económicos de los bosques.

c) El aprovechamiento sostenible de la flora silvestre y de los bosques es una estrategia de conservación y manejo del recurso. Por tanto, el Estado debe crear un ambiente propicio para las inversiones en materia ambiental y para el desarrollo del sector forestal.

d) Gran parte de las áreas boscosas naturales del país se encuentran habitadas; por tanto, se apoyará la satisfacción de las necesidades vitales, la conservación de sus valores tradicionales y el ejercicio de los derechos de sus moradores, dentro de los límites del bien común.

e) Las plantaciones forestales cumplen una función fundamental como fuentes de energía renovable $\mathrm{y}$ abastecimiento de materia prima, mantienen los procesos ecológicos, generan empleo y contribuyen al desarrollo socioeconómico nacional, por lo que se deben fomentar y estimular su implantación (Mecanismos de Información de Páramos s.f).

De acuerdo con lo anterior, entre los principales aspectos que el Decreto 1791 de 1996 consagra, se encuentra la imposición de algunas obligaciones a las Corporaciones Autónomas Regionales (CAR), tales como:

1) Formular y aprobar los planes de ordenación y manejo de bosques.

2) Aplicar de manera prevalente las normas especiales sobre administración, manejo y uso de los recursos naturales.

3) En las regiones en que existe población negra, dar estricto cumplimiento a la Ley 70 de 1993 (Defensoría del Pueblo 2002).

El Decreto 1791 de 1996, en la actualidad es la principal reglamentación forestal. Dicho decreto estableció, en ampliación del Código de Recursos Naturales, los tipos de aprovechamiento, las actividades asociadas al aprovechamiento forestal y, en términos generales, los requerimientos para lograr el aprovechamiento forestal, tanto en bosques naturales como en plantaciones forestales.

Este decreto en comparación con el Decreto Ley 2811 de 1974 amplía el concepto de aprovechamiento forestal y los tipos de aprovechamiento; en tal sentido, lo consagra en su Artículo $1^{\circ}$ de la siguiente manera, el aprovechamiento forestal «es la extracción de productos de un bosque y comprende desde la obtención hasta el momento de su transformación», pues el código de recursos naturales lo define únicamente como «la extracción de productos de un bosque» (República de Colombia 1996A).

En cuanto a las clases de aprovechamiento forestal el Decreto 1791 de 1996 las define de la siguiente forma:

Artículo $5^{\circ}$. Las clases de aprovechamiento forestal son:

a) Únicos. Los que se realizan por una sola vez, en áreas donde con base en estudios técnicos se demuestre mejor aptitud de uso del suelo diferente al forestal o cuando existan razones de utilidad pública e interés social. Los aprovechamientos forestales únicos pueden contener la obligación de dejar limpio el terreno, al término del aprovechamiento, pero no la de renovar o conservar el bosque;

b) Persistentes. Los que se efectúan con criterios de sostenibilidad y con la obligación de conservar el rendimiento normal del bosque con técnicas silvícolas, que permitan su renovación. Por rendimiento normal del bosque se entiende su desarrollo o producción sostenible, de manera tal que se garantice la permanencia del bosque;

c) Domésticos. Los que se efectúan exclusivamente para satisfacer necesidades vitales domésticas sin que se puedan comercializar sus productos.

d) Arboles aislados. Cuando se quiera aprovechar árboles aislados de bosque natural ubicados en terrenos de dominio público o en predios de propiedad privada que se encuentren caídos o muer- 
tos por causas naturales, o que por razones de orden sanitario debidamente comprobadas requieren ser talados, se solicitará permiso o autorización ante la corporación respectiva, que dará trámite prioritario a la solicitud (artículo 55).

e) Usos por ministerio de la ley. De conformidad con lo dispuesto en el artículo 19 de la Ley 70 de 1993, la utilización de recursos naturales renovables para construcción o reparación de vivienda, cercados, canoas y otros elementos domésticos para uso de los integrantes de las comunidades negras de que trata dicha ley se consideran usos por ministerio de la ley, por lo que no requieren permiso ni autorización; dichos recursos, así como el resultado de su transformación, no se podrán comercializar (artículo 22).

De igual forma, el decreto que crea el régimen forestal para Colombia incluye otras clases de aprovechamiento forestal que no fueron establecidas en el Decreto Ley 2811 de 1974, como por ejemplo los aprovechamientos por ministerio de la ley y de árboles aislados (Artículo 26 parágrafos 55, 57, 58 y 59).

Una de las características principales de esta norma, que ha planteado diversos problemas, consiste en la equiparación del aprovechamiento en las plantaciones forestales a los aprovechamientos en el bosque natural, es decir que el aprovechamiento en plantaciones forestales deberá estar supeditado a la obtención de un permiso emitido por la autoridad ambiental del lugar. Esta disposición ha producido grandes inconvenientes porque el aprovechamiento depende en consecuencia de un procedimiento largo y del cumplimiento de diversos requisitos, y su evaluación está sujeta al criterio técnico del funcionario de turno, que bien puede negar el aprovechamiento forestal (Ucros 2008).

Otra regulación importante, en materia de flora, viene a darse con la expedición de la Ley 299 de 1996 con la que se protege la flora colombiana, se reglamentan los jardines botánicos y se dictan otras disposiciones. Establece esta norma que la conservación, la protección, la propagación, la investigación, el conocimiento y el uso sostenible de los recursos de la flora colombiana son estratégicos para el país y constituyen prioridad dentro de la política ambiental. De igual forma, dispone que son de interés público y beneficio social y tendrán prelación en la asignación de recursos en los planes y programas de desarrollo y en el presupuesto general de la Nación y en los presupuestos de las entidades territoriales y de las CAR, (Artículo $1^{\circ}$ Ley 299 de 1996). En cuanto, a los jardines botánicos esta ley expresa, que son «colecciones de plantas vivas cientificamente organizadas, constituidas conforme a esta ley». Además en su Artículo 4 reglamenta la licencia de funcionamiento de los mismos, de tal forma, que para tener derecho a los beneficios, estímulos y prerrogativas contemplados en la Ley 299 de 1996, los jardines botánicos requerirán un permiso expedido por la autoridad ambiental, previo concepto del Instituto de Investigaciones de Recursos Biológicos «Alexander Von Humboldt» (República de Colombia 1996b).En materia de incendios forestales, el país también ha sido enfático en la legislación nacional puesto que, en 1997 se expidió el Decreto 2340 de 1997 con el que se dictan medidas para la organización en materia de prevención y mitigación de incendios forestales. Dicho decreto, establece que el Ministerio de Ambiente como organismo rector de la gestión del medio ambiente y de los recursos naturales renovables y en cumplimiento de su función relacionada con la prevención y atención de desastres, forma parte del Sistema Nacional para la Prevención y Atención de Desastres; de igual forma, crea en el Artículo $3^{\circ}$ la Comisión Nacional Asesora para la Prevención y Mitigación de Incendios Forestales adscrita al Ministerio del Medio Ambiente, con el objeto de servir de órgano asesor en materia de incendios forestales al Sistema Nacional para la Prevención y Atención de Desastres y al Sistema Nacional Ambiental (SINA).

Durante el año 2005, el Gobierno Nacional presentó el proyecto Ley General Forestal, que cursó el trámite en el Congreso Nacional y dio origen a la Ley 1021 de 2006; esta norma aclaraba en buena parte diferentes aspectos relacionados con el manejo del bosque natural, así como de la actividad comercial de las plantaciones forestales. El texto final, que se aprobó en el Congreso, fue elaborado y consultado con el sector productivo, algunas comunidades negras, así como con otras comunidades indígenas; sin embargo, posteriormente a su expedición, la norma fue demandada ante la Corte Constitucional y dicha entidad la declaró inexequible, motivo por el cual fue retirada del ordenamiento jurídico nacio- 
nal mediante sentencia C-030 del 23 de enero de 2008.

El objeto de la Ley Forestal radicaba en establecer el Régimen Forestal Nacional, conformado por un conjunto coherente de normas legales y coordinaciones institucionales, con el fin de promover el desarrollo sostenible del sector forestal colombiano en el marco del Plan Nacional de Desarrollo Forestal. A tal efecto, la ley establecía la organización administrativa necesaria del Estado y regulaba las actividades relacionadas con los bosques naturales y las plantaciones forestales. Esta ley tomó muchos de sus postulados de la Constitución Política de 1991, de la Ley 99 de 1993 y del Decreto 1791 de 1996. Sin embargo, esta ley fue declarada inexequible por la Corte Constitucional Colombiana, situándose por fuera del ordenamiento jurídico, puesto que para su expedición, no se consultaron las comunidades afrodescendientes e indígenas; esta participación democrática debió realizarse por la consagración constitucional como un derecho fundamental de la consulta para la explotación de recursos naturales en sus territorios. Al respecto, del Artículo 6 del Convenio 169 de la OIT (Antonissen 2010).

Es por esta razón que actualmente el manejo y las actividades forestales comerciales siguen siendo regulados por el Decreto 1791 de 1996. Sin embargo, en el año 2007 el Ministerio de Agricultura, a través del Decreto 1498 de 2008 que derogó parcialmente los artículos 70, 71, 72, 73 sobre plantaciones forestales y 74, 75 y 76 sobre movilización de productos forestales y de la flora silvestre, estableció la obligación de registrar las plantaciones forestales con fines comerciales y a su vez, determinó que «La cosecha de los productos obtenidos de los sistemas agroforestales, o cultivos forestales con fines comerciales debidamente registrados, no requerirá autorización alguna por parte de la autoridad ambiental». Posteriormente en el año 2010 este decreto fue derogado por el Decreto Nacional 2803 de 2010.

El Gobierno Nacional en la actualidad expidió la Ley 1450 de 2011 con la que se expide el Plan Nacional de Desarrollo, 2010-2014, que tiene como objetivo consolidar la seguridad con la meta de alcanzar la paz, dar un gran salto de progreso social, lograr un dinamismo económico regional que permita desarrollo sostenible y crecimiento sostenido, más empleo formal y menor pobreza, y en definiti- va, mayor prosperidad para toda la población. En materia forestal el Artículo 60 establece los proyectos especiales agropecuarios o forestales y dispone que «a solicitud del interesado se podrán autorizar actos o contratos en virtud de los cuales una persona natural o jurídica adquiera o reciba el aporte de la propiedad de tierras que originalmente fueron adjudicadas como baldíos o adquiridas a través de subsidio integral de tierras, aun cuando como resultado de ello se consoliden propiedades de superficies que excedan a la fijada para las Unidades Agrícolas Familiares (UAF) por el Instituto Colombiano de Desarrollo Rural (INCODER), siempre y cuando los predios objeto de la solicitud estén vinculados a un proyecto de desarrollo agropecuario o forestal que justifique la operación». De igual forma crea la comisión de proyectos especiales agropecuario y forestal, integrada por los Ministros de Agricultura y Desarrollo Rural, de Hacienda y Crédito Público, de Comercio, de Ambiente, Vivienda y Desarrollo Territorial, hoy Ministerio de Ambiente y Desarrollo Sostenible, o quien haga sus veces, de Industria y Turismo, el Director del Departamento Nacional de Planeación Nacional y el Alto Consejero para la Gestión Pública y Privada de la Presidencia de la República.

Con todo lo anterior, se observa que Colombia ha tenido una muy extensa gama de normas que intentan organizar el régimen y la política forestal y de bosques del país, no obstante, en el caso en concreto, en materia sancionatoria se ha quedado corto. Años atrás, en el ordenamiento que ha regido al país, no se pudo concretar una normatividad que se encargara de limitar directamente a aquellos quienes explotaran, aprovecharan o transportaran los recursos forestales y de la flora silvestre sin los respectivos permisos y/o autorizaciones otorgados por las autoridades ambientales competentes para ello. Sin embargo, es solo en el año 2009 cuando se da pie a la promulgación de la primera ley encargada de consolidar el procedimiento sancionatorio ambiental colombiano, unificando algunos criterios relacionados con los recursos de la fauna y la flora silvestre colombiana. Es así como surge la Ley 1333 de 2009 por la cual se establece el procedimiento sancionatorio ambiental; esta ley, al dedicar alguno de sus apartes a la flora silvestre, establece dentro de los tipos de medidas preventivas la aprehensión preven- 
tiva de especímenes, productos y subproductos de fauna y flora silvestre, al igual que en su artículo 38 define el decomiso y aprehensión preventivos, al expresar que «Consiste en la aprehensión materialy temporal de los especímenes de fauna, flora, recursos hidrobiológicos y demás especies silvestres exóticos y el de productos, elementos, medios, equipos, vehiculos, materias primas o implementos utilizados para cometer la infracción ambiental o producido como resultado de la misma». Además consagra como una de las sanciones la restitución de especímenes de especies de fauna y flora silvestres.

En este orden de ideas, en su estructura, la ley que rige el procedimiento sancionatorio ambiental consagra varias opciones de disposición final de flora silvestre restituidos, en el que fija cada uno de los procedimientos que debe seguir la autoridad ambiental competente mediante acto administrativo para disponer de los individuos o especímenes de flora utilizados para cometer la infracción en cualquiera de las siguientes alternativas: Disposición al medio natural, disposición en Centros de Atención y Valoración (CAV), destrucción, incineración o inutilización, entrega a jardines botánicos, red de amigos de la flora, entrega a viveros $u$ otras organizaciones de conservación como arboretums o reservas forestales y por último, la entrega a entidades públicas en donde la Ley 1333 de 2009 señala, que los productos y subproductos maderables pueden ser entregados a entidades públicas para facilitar el cumplimiento de sus funciones estatales, a través de convenios interinstitucionales que permitan verificar la utilización correcta de los mismos.

Otro aspecto importante, que trae el nuevo procedimiento sancionatorio ambiental es la creación del Registro Único de Infractores Ambientales (RUIA) que está a cargo del Ministerio de Ambiente y deberá contener, al menos, el tipo de falta por la que se sanciona, lugar de ocurrencia de los hechos, sanción aplicada, fecha en que queda ejecutoriado el acto administrativo que impone la sanción y el número, autoridad ambiental que adelantó la investigación y fecha de ejecución o cumplimiento de la sanción, el nombre e identificación del infractor y en caso de ser un persona jurídica aparecerá el nombre de la empresa, NIT y el nombre e identificación del representante legal (Artículo 57 de la Ley 1333 de 2009).
Producto de la promulgación de la Ley 1333 de 2009, se expide más adelante la Resolución 2064 de 2010 , siendo el objeto de esta, reglamentar las alternativas de disposición provisional y final de especímenes de especies silvestres de fauna y flora terrestre y acuática, que aplicarán las autoridades ambientales competentes en los casos de aprehensión preventiva, restitución o decomiso definitivo de dichos especímenes. Asimismo, reglamentar el Portal de Información sobre Fauna Silvestre (PIFS) (Ministerio Ambiente 2010). También se encarga esta resolución de conceptuar sobre otros aspectos al definir la aprehensión preventiva como "la medida impuesta por la autoridad ambiental mediante acto administrativo, que consiste en el acto físico de tomar posesión de un espécimen de fauna oflora silvestre de manera temporal» y el decomiso definitivo como «la sanción administrativa impuesta por la autoridad ambiental mediante acto administrativo motivado, que consiste en la aprehensión material y definitiva sobre aquellos especímenes de especies exóticas silvestres de fauna y flora terrestre o acuática, y de los productos, elementos, medios e implementos utilizados para infringir las normas ambientales», en los términos que señalan la Ley 1333 de 2009, el parágrafo del Artículo 38, el numeral 5 del Artículo 40 y el Artículo 47, y el Decreto Ley 2811 de 1974 y sus decretos reglamentarios. Otro aporte que introduce la precitada resolución, se relaciona con la restitución de especímenes de especies de flora y fauna silvestres al contemplarla como la acción de devolver al Estado los especímenes aprehendidos incluyendo el valor de todos los costos incurridos desde el momento de la aprehensión hasta su disposición final (Ministerio de Ambiente, Vivienda y Desarrollo Territorial 2010).

Con la expedición de la ley sobre régimen sancionatorio ambiental y la resolución que lo reglamentó, el ordenamiento jurídico colombiano no se quedó estático, porque, luego en materia forestal en el país se expidieron nuevas leyes y decretos como es el caso de la Ley 1377 de 2010, por medio de la cual se reglamentaba la actividad de reforestación comercial, siendo el objeto de esta ley definir y reglamentar las plantaciones forestales y sistemas agroforestales con fines comerciales (República de Colombia 2010A), además, esta Ley en su Artículo $3^{\circ}$ establecía que el Ministerio de Agricultura y De- 
sarrollo Rural, como órgano rector de la producción agropecuaria, forestal y pesquera, es la única entidad competente para formular la política del sector forestal comercial y sistemas agroforestales, así como el otorgamiento y reglamentación del Certificado de Incentivo Forestal (CIF), para el apoyo de programas de reforestación comercial. Esta ley deroga parcialmente los artículos 70, 71, 72, 73, 74, 75 y 76 del Decreto 1791 de 1996, decreto por el cual se rige de forma unánime el régimen de aprovechamiento forestal de Colombia; sin embargo, la Ley 1377 de 2010, ya fue excluida del ordenamiento colombiano, al ser declarada inexequible por la Corte Constitucional mediante Sentencia C-685 de 2011 por la ausencia de publicidad en la convocatoria a sesiones extraordinarias, lo que configura un vicio de inconstitucionalidad insubsanable, pues dicha ley fue aprobada en sesiones efectuadas sin el lleno de los requisitos constitucionales.

A raíz de la promulgación de la Ley 1377 de 2010, surge en el mismo año el Decreto 2803 de 2010 que se encargó de reglamentar la Ley en lo atinente al registro de cultivos forestales y sistemas agroforestales con fines comerciales, de plantaciones protectoras-productoras, la movilización de productos forestales de transformación primaria. Se encargó además de dictar otras disposiciones que establecen que las plantaciones forestales protectoras-productoras y sistemas agroforestales financiados con recursos del Sistema Nacional Ambiental (SINA) y/o personas naturales o jurídicas públicas y privadas con fines de protección o recuperación de recursos naturales renovables y/o prestación de servicios ecosistémicos, se registrarán ante las corporaciones autónomas regionales y de desarrollo sostenible, disponiendo de otra forma, que las plantaciones forestales y/o sistemas agroforestales establecidos como medidas de compensación en razón del otorgamiento de aprovechamientos forestales únicos o en desarrollo de licencias ambientales, entre otros, también deberán registrarse ante las corporaciones autónomas regionales y de desarrollo sostenible (República de Colombia 2010b).

Habiéndose hecho un análisis de las diferentes normas que sobre recursos forestales y de bosques se han expedido en Colombia, se reconoce, grosso modo, que algunas han sentado precedente al unificar o consolidar la legislación nacional sobre el tema, como es el caso del Decreto Ley 2811 de 1974 Código Nacional de Recursos Naturales y del Ambiente, y el Régimen de Aprovechamiento Forestal Decreto 1791 de 1996 que aún sigue vigente pese a que se ha intentado expedir una ley forestal. Se pasa entonces a determinar aspectos relevantes sobre el aprovechamiento forestal frente a las comunidades negras, teniendo en cuenta que este artículo es producto de la parte preliminar del proyecto «estudio jurídico sobre el otorgamiento de permisos de aprovechamiento forestal en territorios colectivos de comunidades negras del departamento del Chocó entre 20042009».

El aprovechamiento forestal frente a las comunidades negras. En relación con las comunidades negras en materia de bosques y de aprovechamiento forestal la Constitución Política de 1991, consagra el Artículo 55 transitorio que ordenó al Congreso la expedición de una ley que le reconociera a las comunidades negras que han venido ocupando las tierras baldías en las zonas rurales ribereñas a la cuenca del Pacífico, el derecho a la propiedad colectiva de las mismas, de acuerdo con sus prácticas tradicionales (Perea 1998). Es así como el artículo transitorio constitucional da los primeros lineamientos para que se expida la Ley 70 de 1993 sobre mecanismos para la protección de la identidad cultural y de los derechos de las comunidades negras de Colombia; esta norma define dentro de su artículo $2^{\circ}$ las prácticas tradicionales de producción, como las actividades y técnicas agrícolas, mineras, de extracción forestal, pecuarias, de caza, pesca y recolección de productos naturales en general, que han utilizado consuetudinariamente las comunidades negras para garantizar la conservación de la vida y el desarrollo autosostenible (República de Colombia 1993b). Con respecto a los suelos y los bosques incluidos en la titulación colectiva, dispone que «la propiedad se ejercerá en función social y le es inherente una función ecológica». En consecuencia, dispone que tanto el uso de los bosques que se ejerza por ministerio de la ley, como los aprovechamientos forestales con fines comerciales deberán garantizar la persistencia del recurso. Para adelantar estos últimos se requiere autorización de la entidad competente para el manejo del recurso forestal (República de Colombia 1993b).

En materia de permisos de aprovechamiento fo- 
restal en los territorios colectivos de comunidades negras, la Ley 70 ha dispuesto en su Artículo 24 que la entidad administradora de los recursos naturales renovables reglamentará concertadamente con las comunidades negras el uso colectivo de áreas del bosque a que se refiere dicha ley, para el aprovechamiento forestal persistente. Además, establece que para efectos del aprovechamiento, el procesamiento o la comercialización de los productos forestales que se obtengan en desarrollo de la concesión forestal, la comunidad concesionaria podrá entrar en asociación con entidades públicas o privadas. Al mismo tiempo consagra el deber del Estado colombiano de garantizar y facilitar la capacitación de los integrantes de las comunidades concesionarias en las prácticas y técnicas adecuadas para cada etapa del proceso de producción para asegurar el éxito económico y el desarrollo sustentable de los integrantes y de la región.

La Ley 70 se encarga así, de crear en armonía con el Artículo 13 de la Constitución Política de Colombia, la prioridad para los integrantes de comunidades negras cuando se trata de explotación de los recursos forestales.

En cuanto a la tenencia forestal, la misma norma estableció que «Salvo los suelos y los bosques, las adjudicaciones colectivas que se hagan conforme a esta ley no comprenden:

a) El dominio sobre los bienes de uso público,

b) Las áreas urbanas de los municipios,

c) Los recursos naturales renovables y no renovables,

d) Las tierras de resguardos indígenas legalmente constituidos,

e) El subsuelo y los predios rurales en los cuales se acredite propiedad particular conforme a la Ley 200 de 1936,

f) Las áreas reservadas para la seguridad y defensa nacional,

g) Áreas del sistema de parques nacionales.»

Con respecto a los suelos y los bosques incluidos en la titulación colectiva, dispone la precitada ley que la propiedad se ejercerá en función social y le es inherente una función ecológica. En consecuencia, para el uso de estos recursos se tendrá en cuenta, en primer lugar que tanto el uso de los bosques que se ejerza por ministerio de la ley, como los aprovechamientos forestales con fines comerciales de- berán, garantizar la persistencia del recurso; para lo cual se requiere autorización de la entidad competente para el manejo del recurso forestal y en segundo lugar, que el uso de los suelos se haga teniendo en cuenta la fragilidad ecológica de la Cuenca del Pacífico, en consecuencia los adjudicatarios desarrollarán prácticas de conservación y manejo compatibles con las condiciones ecológicas. Para tal efecto se desarrollarán modelos apropiados de producción como la agrosilvicultura y la agroforestería u otros similares, desarrollando los mecanismos idóneos para estimularlos y para desestimular las prácticas ambientalmente insostenibles.»

La disposición en comento determinó que la titulación de tierras a las comunidades negras, bajo la figura de la propiedad privada colectiva, incluyese de manera clara la adjudicación del suelo y el bosque a dichas comunidades. Esto implica, en términos de propiedad, tenencia y administración y manejo de los recursos forestales, que se obedecen en dichos territorios los criterios de uso y manejo propios de las prácticas tradicionales de las comunidades negras, dentro de la función ecológico-social de la propiedad (Ucros 2008).

Por otra parte, la norma establece la obligación de «observar las normas sobre conservación, protección y utilización racional de los recursos naturales renovables y el ambiente».

Al ser la Ley 70 de 1993, una de las primeras normas formuladas bajo la nueva Constitución Política de 1991 y de importancia para las comunidades negras, teniendo en cuenta los preceptos del estado social de derecho, dicha Ley en 1995 fue reglamentada parcialmente por el Decreto 1745 que dedica algunos de sus apartes a la organización de los consejos comunitarios de comunidades negras, estableciendo que los consejos comunitarios están conformados por la asamblea general y que como persona jurídica ejercen la máxima autoridad en las tierras de comunidades negras (Artículo 3 y ss.).

En cuanto a las comunidades negras y su relación con los recursos forestales, las anteriores normas, entre otras, pretenden asegurar cabalmente los derechos de estas comunidades y evitar que actividades ajenas a su cultura y a sus tradiciones productivas, como la explotación mecanizada e indiscriminada de los recursos forestales afecten su subsistencia, integridad e identidad colectiva, aspectos que 
históricamente habían sido desconocidos.

Adicionalmente a lo anterior, en lo referente al carácter de los derechos en cabeza de los pueblos negros, hay que tener en cuenta que de su reconocimiento como grupo étnico se desprende el que sean titulares de derechos colectivos similares a los de las comunidades indígenas, con las diferencias impuestas por sus especificidades culturales y su régimen legal propio. Además, es de resaltar que por ser reconocidas como grupos étnicos, las comunidades negras «se hacen acreedoras a los derechos que consagra el 169 de la OIT» Corte Constitucional de Colombia (2010, Sentencia C-169 de 2001), tales como el derecho a la consulta previa, no solo para la exploración y explotación de los recursos naturales en territorios étnicos sino también para adopción de medidas legislativas o administrativas, y el derecho a la participación en órganos administrativos.

El derecho de las comunidades negras frente al aprovechamiento de los recursos forestales yacentes en sus territorios colectivos, jurisprudencialmente también ha sido objeto de avance, pues este derecho se encuentra sustentado claramente en la sentencia T 955 de 2003 en donde la Corte Constitucional Colombiana ha expresado que «El derecho de las comunidades negras sobre su territorio colectivo se funda en la Carta Política y en el Convenio 169 de la OIT, sin perjuicio de la delimitación de sus tierras a que se refiere la Ley 70 de 1993, en cuanto ésta resulta definitiva e indispensable para que dichas comunidades puedan ejercer las acciones civiles a que da lugar el reconocimiento constitucional. Y que el derecho de propiedad colectiva en comento comprende, y siempre comprendió la facultad de las comunidades negras de usar, gozar y disponer de los recursos naturales renovables existentes en sus territorios, con criterios de sustentabilidad.»

En el mismo pronunciamiento reitera la Corte que «Desde el año de 1967, en los términos de la Ley 31, a las comunidades negras nacionales, en cuanto pueblos tribales, les fue reconocido el derecho a la propiedad colectiva de los territorios que ocupan ancestralmente $y$, por ende, las facultades de uso y explotación de sus suelos y bosques, esto último, por ministerio de la ley o previa autorización de la autoridad ambiental, en los términos del Código de Recursos Naturales». Corte Constitucional de Colombia (2003, Sentencia T-955 de 2003).
Estos aspectos se relacionan con el hecho de que el Congreso nacional acogió la comprensión de los bosques y suelos en la propiedad colectiva que la Carta Política les reconoce a las comunidades negras, reafirmando la función social y ecológica de dicha propiedad.

En relación con lo expuesto y en defensa del derecho de las comunidades negras, las autoridades de la República, en especial las ambientales, están en el deber de apoyar a las comunidades negras en las acciones que emprendan para impedir el uso de la tierra y la explotación de sus recursos naturales por personas ajenas, y sancionar a quienes se aprovechen ilegalmente de los productos de los suelos y bosques de sus territorios colectivos. Mandatos estos que operan para la tala doméstica y para la que se adelante con fines de comercialización, porque son las comunidades negras las que pueden aprovechar los recursos forestales de su territorio colectivo, sin perjuicio de su derecho a asociarse en condiciones de igualdad, con entidades públicas o privadas, para adelantar aprovechamientos forestales sostenibles.

El departamento del Chocó, en cuanto al aprovechamiento forestal, debe asumir un rol de competencia a través de la Corporación Autónoma Regional para el Desarrollo Sostenible del Chocó, lo anterior basado en la Resolución 540 de 1997, por la cual se definió el procedimiento para los Planes de Aprovechamiento Forestal (PAF) y se establecieron los cupos para el Chocó, debido a que el artículo 3 de esta resolución reproduce la facultad del Ministerio del Medio Ambiente para ejercer evaluación y control sobre los permisos de aprovechamiento forestal y ordenar la suspensión de los mismos (Ley 99 de 1993, artículos 5-16). Y por consiguiente, el artículo 6 reitera que CODECHOCO debe dar cumplimiento a las leyes sobre grupos étnicos y a las del medio ambiente (Defensoría del Pueblo 2002).

Lo anterior, porque en el departamento del Chocó, la explotación y comercialización de la madera se hace de manera desorganizada y técnicamente deficiente. La deforestación causada por la tala indiscriminada, las pérdidas de grandes volúmenes de madera y la pobreza a la que se enfrentan los campesinos, representa un grave problema socioeconómico para la región, ante la falta de alternativas de desarrollo, producción, empleo rural y condicio- 
nes de marginalidad en que permanecen estas comunidades (CODECHOCO, 2009 citado por Cuesta, s.f.). Por esta razón se debe lograr, según lo planteado por CODECHOCÓ (2011), que las comunidades negras e indígenas como principales receptoras de las autorizaciones de aprovechamiento forestal en el Chocó, se empoderen de este y establezcan controles al aprovechamiento, de tal forma, que estas comunidades más que utilizar los salvoconductos como venta de bazar, los utilicen para garantizar un aprovechamiento sostenible.

\section{Conclusiones}

1. Se identificó que en materia forestal en el país, las autoridades que tienen competencia son el Ministerio de Agricultura y Desarrollo Rural y el Ministerio de Ambiente y Desarrollo Sostenible. Al primero de estos, le corresponde definir la política forestal productiva, entendiendo como tal la explotación forestal y la reforestación comercial, asignadas en virtud de la Ley 101 de 1993 y del Decreto 1172 de 1999. En consecuencia, le compete la administración y financiación de incentivos para la reforestación protectora-productora y la comercialización a través de instrumentos económicos como el Certificado de Incentivo Forestal de Reforestación (CIF). Por su parte, el Ministerio de Ambiente y Desarrollo Sostenible como la máxima autoridad ambiental es la encargada de coordinar la formulación del Plan Nacional de Desarrollo Forestal (Ley 37 de 1989), estructurar, implementar y coordinar el Servicio Forestal Nacional y establecer el Régimen de Aprovechamiento Forestal (Decreto 1791 de 1996). Sin embargo, a las corporaciones autónomas regionales y de desarrollo sostenible les corresponde entre otras funciones, otorgar permisos y concesiones para aprovechamientos forestales, al igual que reservar, alinderar, y administrar en los términos y condiciones que fijen la ley y los reglamentos, los distritos de manejo integrado, los distritos de conservación de suelos, las reservas forestales y parques naturales de carácter regional, y reglamentar su uso y funcionamiento. Administrar las reservas forestales nacionales en el área de su jurisdicción.

2. La Ley $2^{\mathrm{a}}$ de 1959 , es una de las normas de ma- yor importancia en materia forestal de Colombia, con ella se adoptó por primera vez la figura de parque nacional natural, con el fin de conservar la flora y la fauna nacionales, y facultó al Gobierno Nacional para que delimitara y reservara de manera especial zonas del país en sus distintos pisos térmicos como parques nacionales naturales, donde para cumplir la finalidad de conservación, quedaba prohibida la adjudicación de baldíos, las ventas de tierras, la caza y toda actividad industrial, ganadera o agrícola, distinta a la del turismo o aquellas que el gobierno nacional considerara inconvenientes para la conservación o embellecimiento de la zona, creando así, siete zonas de reserva forestal.

3. Los dos cuerpos legales vigentes más importantes para la gestión de los recursos forestales en Colombia son el Código Nacional de Recursos Naturales Renovables y de Protección al Medio Ambiente (Decreto 2811 del 18/10/1974) y el Régimen de Aprovechamiento Forestal (Decreto 1791 del 04/10/1996). El primero tiene por objetivo, regular el manejo de los recursos naturales renovables (flora, fauna y los recursos del paisaje, entre otros) y la defensa del ambiente y de los recursos naturales renovables contra la acción nociva de fenómenos naturales, y otros elementos y factores que conforman el ambiente o influyen en él, denominados en el Código como «elementos ambientales». El segundo, regula las actividades de la administración pública y de los particulares respecto al uso, manejo, aprovechamiento y conservación de los bosques y la flora silvestre, con el fin de lograr un desarrollo sostenible.

4. En el departamento del Chocó, las comunidades negras son las principales receptoras de las autorizaciones de aprovechamiento forestal; sin embargo, no realizan controles para garantizar un aprovechamiento sostenible de los recursos forestales y del bosque, porque se dedican a utilizar los salvoconductos que le expide la autoridad ambiental de la región como una venta de bazar.

\section{Agradecimientos}

Las autoras expresan sus agradecimientos a la Universidad Tecnológica del Chocó «DLC», al De- 
partamento Administrativo de Ciencia Tecnología e Innovación (COLCIENCIAS) por el apoyo en el proceso de formación de la Joven Investigadora y al señor Gonzalo Díaz Cañadas por la información suministrada.

\section{Literatura citada}

Antonissen, M. 2010. Requerimientos institucionales y legales de los países de América Latina para la implementación de un mecanismo de Reducción de Emisiones por Deforestación y Degradación (REDD+). Estructuras institucionales y legales forestales de seis países de América Latina: Brasil, Costa Rica, México, El Salvador, Colombia, Chile. En línea [Fecha de acceso: 8 de noviembre de 2010]. URL disponible en: http://www.gtzcepal.cl/files/2010-06_antonissen.pdf

CODECHOCÓ. 2011. Foro: Gobierno en línea perspectivas del aprovechamiento forestal comunidades negras e indigenas. En línea [Fecha de acceso: 15 de octubre de 2011]. URL disponible en: http://www.codechoco.gov.co/ index.php?option $=$ com_kunena\&func $=$ view\&catid $=5 \& \mathrm{id}=$ 46\&Itemid $=108$

Convención de la Cumbre de Río de Janeiro. 1992. La Conferencia de las Naciones Unidas sobre el Medio Ambiente y el Desarrollo (CNUMAD). Cumbre para la Tierra. En línea. [Fecha de acceso: $1^{\circ}$ de octubre de 2011]. URL disponible en: http://es.wikipedia.org/wiki/ Cumbre_de_la_Tierra_de_R\%C3\%ADo_de_Janeiro

Corte Constitucional de Colombia. 2001. Sentencia C-169 de 2001. República de Colombia.

Corte Constitucional de Colombia. 2003. Sentencia T-955 de 2003. República de Colombia.

Corte Constitucional de Colombia. 2008. Sentencia C-030 de 2008. República de Colombia.

Corte Constitucional de Colombia. 2011. Sentencia C-685 de 2011. República de Colombia.

Cuesta T. S.f. «El Chocó siembra el futuro». En línea [Fecha de acceso: 10 de noviembre de 2011]. URL disponible en: http://200.26.134.109:8091/unichoco/hermesoft/portal/ home_1/htm $/$ cont $0 . j s p ?$ rec $=$ not_2182.jsp

Defensoría del Pueblo. 2002. Explotación maderera y derechos humanos, Bajo Atrato, Chocó. Bogotá: Imprenta Nacional de Colombia; 11-47 p.

Díaz-Cano M. 2008. Conflicto de ocupación en áreas protegidas Conservación versus derechos de comunidades. En línea [Fecha de acceso: 17 de junio de 2011]. URL disponible en: http://www.udem.edu.co/NR/rdonlyres/D1F726A4CE 75-4 A 1 5-966 B - C67718C06F49/10931/ Artculo3reasprotegidas.pdf

Mecanismos de Información de Páramos. S.f. Decreto 1791 de 1996: Régimen de aprovechamiento forestal para Colombia. En línea [Fecha de acceso: 28 de abril de 2011]. URL disponible en: http://www.paramo.org/node/350

Ministerio de Ambiente, Vivienda y Desarrollo Territorial. S.f. Atlas temático, zonas de reserva forestal Ley $2^{a}$ de 1959. En línea [Fecha de acceso: 24 de noviembre de 2011].
URL disponible en: http://www.siac.gov.co/documentos/ DOC_Portal/DOC_Bosques/26092011_atlas\%20zonas\% $20 \mathrm{de} \% 20$ reserva $\% 20$ forestal.pdf

Ministerio de Ambiente, Vivienda y Desarrollo Territorial. 2010. Resolución 2064 de 2010, por la cual se reglamentan las medidas posteriores a la aprehensión preventiva, restitución o decomiso de especímenes de especies silvestres de fauna y flora terrestre y acuática y se dictan otras disposiciones. Colombia.

Ministerio del Medio Ambiente. 1994. Revisión y clasificación de la legislación forestal colombiana en INDERENA Ministerio del Medio Ambiente. Lineamientos y estrategias de la política para el desarrollo forestal sustentable. Bogotá: Organización Internacional de Maderas Tropicales; $126-8 \mathrm{p}$.

Ministerio del Medio Ambiente. 2002. Criterios e indicadores para la ordenación sostenible de los bosques naturales. Bogotá: República de Colombia.

Murillo-Trujillo, J.E. 2008. El marco legal forestal colombiano enfocado al manejo de los recursos naturales en Colombia: Estado del Arte. En línea [Fecha de acceso: 5 de mayo de 2011]. URL disponible en: http://www.aciem. org/bancoconocimiento/E/Elmarcolegalforestal colombiano/MARCO\%20LEGAL\%20FORESTAL.doc

Ortiz-Herrera, A.E. S.f. Historia agraria de Colombia, 19261930 o el fin de la hegemonía conservadora. En línea [Fecha de acceso: 1 de noviembre de 2011]. URL disponible en: http://www.villarrica.galeon.com/historia/ colombia.pdf

Pacto por los bosques del país. S.f. Golpe a los comerciantes de madera ilegal tras 'Pacto por los bosques del pais'. En línea [fecha de acceso: 10 de octubre de 2011]. URL disponible en: http://www.revista-mm.com/ediciones/ rev65/forestal_maderalegal.pdf

Pacto intersectorial por la madera legal en Colombia. 2010. Panorama forestal actual en Colombia. Publicación del Proyecto Bosques FLEGT/Colombia (CARDER/Unión Europea). En línea [Fecha de acceso: 11 de mayo de 2011]. URL disponible en: http:/guaduaymadera.blogspot.com/ 2010/11/panorama-forestal-actual-en-colombia.html

Parques Nacionales Naturales de Colombia. 2010. Creación de nuevas áreas. En línea [Fecha de acceso: 14 de junio de 2011]. URL disponible en: http://www.parquesnacionales. gov.co/PNN/portel/libreria/pdf/publi3.pdf

Perea, F. A. 1998. Derecho y medio ambiente: las minorias étnicas y el medio ambiente Medellín: Biblioteca Jurídica DIKE; $58 \mathrm{p}$.

Pizano S. A. s.f. Balsa: hacia una cultura del bosque. Bogotá: Maderas del Darién SA; 26 p.

República de Colombia. 1919. Ley 119 de 1919. Por la cual se reforma el Código Fiscal (Ley 110 de 1912), sobre explotación de bosques nacionales. Colombia.

República de Colombia. 1920. Decreto 272 de 1920. Por el cual se reglamenta la Ley 119 de 1919 sobre explotación de bosques nacionales. Colombia.

República de Colombia. 1920. Decreto 2227 de 1920. Por la cual se fija el límite máximo de concesión de 15,000 hectáreas. Colombia.

República de Colombia. 1926. Ley 74 de 1926. Sobre fomento 
a la agricultura y a la inmigración y se dictan otras disposiciones. Colombia.

República de Colombia. 1931. Ley 93 de 1931. Por la cual se fomenta la explotación de productos forestales. Colombia.

República de Colombia. 1942. Decreto 1454 de 1942. Sobre fomento forestal. Colombia.

República de Colombia. 1946. Decreto 2921 de 1946. Por el cual se dictan medidas sobre explotación de bosques. Colombia.

República de Colombia. 1953. Decreto 2278 de 1953. Por la cual se dictan medidas sobre cuestiones forestales. Colombia.

República de Colombia. 1931. Ley 93 de 1931. Por la cual se fomenta la explotación de productos forestales. Colombia.

República de Colombia. 1959. Ley $2^{a}$ de 1959. Sobre economía forestal de la nación y conservación de los recursos naturales renovables. Colombia.

República de Colombia. 1967. Ley 31 de 1967. Por la cual se aprueba el Convenio Internacional del Trabajo, relativo a la protección e integración de las poblaciones indígenas y tribuales en los países independientes. Adoptado por la Cuadragésima Reunión de la Conferencia General de la Organización Internacional del Trabajo (Ginebra 1957). Colombia.

República de Colombia. 1973. Ley 23 de 1973. Por la cual se concede las facultades para la expedición del código nacional de recursos naturales y de protección al medio ambiente. Colombia.

República de Colombia. 1974. Decreto 2811 de 1974, mediante el cual se dicta el Código Nacional de Recursos Naturales Renovables y de Protección al Medio Ambiente. Colombia.

República de Colombia. 1981. Ley 17 de 1981, mediante la cual se aprueba la "Convención sobre el Comercio Internacional de Especies Amenazadas de Fauna y Flora Silvestres», suscrita en Washington, DC, el 3 de marzo de 1973. Colombia.

República de Colombia. 1982. Decreto 1014 de 1982. Por el cual se reglamentan los artículos 55, 60 y 216 del Decreto - Ley 2811 de 1974, y se derogan los Decretos 2151 y 2152 de 1979. Colombia.

República de Colombia. 1989. Ley 37 de 1989, la cual establece las bases para estructurar el plan nacional de desarrollo forestal. Colombia.

República de Colombia. 1991. Constitución Política de Colombia de 1991. Colombia.

República de Colombia. 1993a. Ley 99 de 1993, mediante la cual se crea el Ministerio del Medio Ambiente, se reordena el sector público encargado de la gestión y conservación del medio ambiente y los recursos naturales renovables, se organiza el Sistema Nacional Ambiental (SINA) y se dictan otras disposiciones. Colombia.

República de Colombia. 1993b. Ley 70 de 1993, mediante la cual se desarrolla el Artículo transitorio 55 de la Constitución Política. Colombia.

República de Colombia. 1994. Decreto 2925 de 1994. Creación de la Unidad Administrativa del Sistema de Parques Nacionales Naturales de Colombia (UAESPNN). Colombia.
República de Colombia. 1994. Decreto 1824 de 1994. Por el cual se reglamenta parcialmente la Ley 139 de 1994. Colombia.

República de Colombia. 1996a Decreto 1791 de 1996. Por el cual se regula el aprovechamiento forestal en el país. Colombia.

República de Colombia. 1996B. Ley 299 de 1996. Por la cual se protege la flora colombiana, se reglamentan los jardines botánicos y se dictan otras disposiciones. Colombia.

República de Colombia. 1997. Decreto 900 de 1997. Por el cual se reglamenta el Certificado de Incentivo Forestal para Conservación. Colombia

República de Colombia. 1997. Decreto 622 de 1997. Por el cual se reglamenta el Capitulo V, Título II, Parte XIII, Libro II del Decreto-Ley número 2811 de 1974 sobre "Sistema de Parques Nacionales»; la Ley 23 de 1973 y la Ley $2^{a}$ de 1959. Colombia.

República de Colombia. 1997. Decreto 2340 de 1997. «Por el cual se dictan medidas para la organización en materia de prevención y mitigación de incendios forestales y se dictan otras disposiciones». Colombia.

República de Colombia. 2006. Ley 1021 de 2006. Por la cual se expide la "Ley Forestal», Declarada inexequible por la Corte Constitucional Colombiana el 23 de enero de 2008. Colombia.

República de Colombia. 2008. Decreto 1498 de 2008. Por el cual se reglamenta el parágrafo $3^{\circ}$ del artículo $5^{\circ}$ de la Ley 99 de 1993 y el artículo 2 de la Ley 139 de 1994. Colombia.

República de Colombia. 2009. Ley 1333 de 2009, mediante la cual se establece el procedimiento sancionatorio ambiental y se dictan otras disposiciones. Colombia.

República de Colombia. 2010a. Ley 1377 de 2010. Por la cual se reglamenta la actividad de reforestación comercial. Colombia

República de Colombia. 2010b. Decreto 2803 de 2010. Por el cual se reglamenta la Ley 1377 de 2010 enero 8, por medio de la cual se reglamenta la actividad de reforestación comercial. Colombia.

República de Colombia. 2011. Ley 1450 de 2011. Por la cual se expide el Plan Nacional de Desarrollo, 2010-2014. Colombia.

Toro-Jaramillo, I. D., Parra-Ramírez, R. D. 2010. Fundamentos epistemológicos de la investigación y la metodología de la investigación cualitativa/cuantitativa. Bogotá: Fondo Editorial EAFIT; $412 \mathrm{p}$.

Ucros, J. C. 2008. Breve historia y situación actual del patrimonio forestal colombiano: Contexto nacional actual, organización del Estado y regulación jurídica de los recursos forestales. En línea [Fecha de acceso: 19 de agosto de 2011]. URL disponible en: http://www.fao.org/ forestry/ $17272-09$ c 7 bb 88 cbaad 85 cf5 c 312 d 84 22b30afb.pdf

Universidad Nacional de Colombia. 2011. Debate Nacional para una política forestal pública: Replantémonos. En línea [Fecha de acceso: 25 de septiembre de 2011]. URL disponible en: http://www.replantemonos.unal.edu.co/ 